\title{
JACQUELINE ASSAËL, ANNE-MARIE FAVREAU- LINDER. SILVES GRECQUES 2015-2016. EURIPIDE, ALCESTE. LUCIEN, CHARON, VIES DES PHILOSOPHS À L'ENCAN, LE PÊCHEUR, LA DOUBLE ACCUSATION Pilar Gómez Universitat de Barcelona pgomez@ub.edu
}

Recibido: 1 septiembre 2015 Aceptado: 30 octubre 2015

Jacqueline Assaël, Anne-Marie Favreau-Linder. Silves grecques 2015-2016. Euripide, Alceste. Lucien, Charon, Vies des philosophes à l'encan, Le Pêcheur, La Double accusation. Neully: Atlande, 2015. ISBN 978-2-35030-285-0.

La revista Silves -Latines et Grecques- publica anualmente en la colección Clefs concours volúmenes dedicados a los temas que constituyen el programa anual de distintos concursos, especialmente el de Agrégation y el de CAPES. Este año, uno de los volúmenes correspondientes a la sección de letras clásicas, está firmado por Jacqueline Assaël (profesora en la Université de Nice Sophia-Antipolis) y Anne-Marie Favreau-Linder (profesora en la Université Blaise-Pascal de Clermont-Ferrand). El volumen Silves grecques 2015-2016 reúne, como es habitual, dos autores griegos de períodos y géneros distintos; en esta ocasión, un poeta dramático de época clásica (Eurípides) y un prosista de época imperial romana (Luciano de Samosata). Del autor trágico, la obra elegida es Alcestis, mientras que de Luciano se han escogido cuatro opúsculos: Caronte, Subasta de vidas, Pescador y Doble acusación.

En ambos casos, el material está organizado de acuerdo con la estructura común a toda la colección, cuyo objetivo es ofrecer referencias generales sobre el contexto literario e histórico en el que se sitúa el autor y su obra; abordar cuestiones indispensables para una buena comprensión del tema que plantean los textos seleccionados; proporcionar recursos de lengua, 
estilística, gramática..., específicos según la tipología de las obras; presentar instrumentos metodológicos (glosarios, léxicos, bibliografía...) que contribuyen, sin duda, a sintetizar la información y a interpretar mejor las obras propuestas.

\section{Euripide, Alceste}

En el presente volumen, las breves páginas dedicadas a la biografía, obra, contexto cultural, social, intelectual y político de Eurípides se presentan en el epígrafe INTRODUCTION (pp. 23-30), mientras que el grueso del estudio se centra en Alcestis, tanto en lo que respecta a las particularidades de la mise en scène de esta pieza como a su lectura analítica, abordadas ambas en la sección REPÈRES (pp. 35-65). Esta y la sección titulada PROBLÉMATIQUES (pp. 67-105) constituyen la parte expositiva, teórica y de análisis de la obra más antigua conservada (438 a.C.) de Eurípides cuyo desenlace, calificado como "más bien cómico" en el argumento atribuido a Aristóteles de Bizancio, ha llevado a poner en duda desde la antigüedad misma la naturaleza estrictamente trágica de esta pieza y ha favorecido su posible asimilación a un drama satírico.

La virtud de un trabajo importante de síntesis como el que exige un libro de estas características obliga $-\mathrm{y}$ este constituye uno de sus grandes aciertos- a considerar, sin embargo, múltiples aspectos contextuales de una pieza dramática. No obstante, a pesar de su breve extensión, este estudio como se echa de ver en el exhaustivo índice- no se limita a enumerar una serie de motivos de índole diversa -contexto histórico, organización de las representaciones teatrales, evolución del género dramático, papel de los dioses en la obra, representación del duelo, creación de espacios imaginarios...- sino que los describe mediante una explicación concisa, aunque no por ello menos precisa, que remite a la bibliografía específica y a otros apartados del mismo estudio. De este modo, se tratan tanto cuestiones formales -por ejemplo, la arquitectura de un teatro (pp. 38-41), que se acompaña con el plano correspondiente, o el número de actores y sus máscaras (pp. 41-43) - como de contenido, pues se explica la vinculación de las representaciones dramáticas a la vida religiosa y política de la ciudad (pp. 35-38), o se ofrece una definición del género tragedia, que, a su vez, Assaël amplia aportando el significado de nociones fundamentales en el análisis literario de una tragedia, tales como Dramatique, Pathétique, Tragique, Fantastique o Merveilleux (pp. 47-49), que después serán retomados en el examen específico de Alcestis -a modo de ejemplo, puede señalarse el apartado LE TRAGIQUE DANS ALCESTE (pp. 86-96). 
La lectura analítica de la pieza (pp. 49-60) está hecha atendiendo a la división formal de una tragedia: prólogo, parodos, primer episodio, primer stasimon, segundo episodio, segundo stasimon, tercer episodio, tercer stasimon y éxodo. En este análisis cada una de las partes va identificada con referencia a los versos que incluye, pero resulta especialmente apropiado y valioso que una breve frase reseñe su contenido general -Premier épisode : mort d'Alceste (v. 136-434)-, así como las diversas subdivisiones Première phase : annonce de l'imminence de cette mort par la servante (v. 136-212)...-, puesto que de forma visual y sucinta tales indicaciones marcan el desarrollo de la pieza. Las partes corales y los pasajes líricos, además, son descritos desde el punto de vista de su estructura: "Le chœur rend hommage à Alceste, au cours de ce morceau lyrique composé de deux couples de strophe et antistrophe" (p. 55, a propósito del primer stasimon cuyo contenido es sintetizado como "célébration d'Alceste" (vv. 435-475). Solo en la descripción del parodos se hace referencia al tipo de verso utilizado.

En la sección PROBLÉMATIQUES (pp. 67-105) se abordan cuestiones fundamentales que permiten orientar de forma rigurosa la interpretación del conflicto presentado en Alcestis, ante todola debatida cuestión de la relación entre esta obra y el drama satírico, las fuentes del mito de Alcestis, el uso que Eurípides hace de la tradición literaria precedente, e incluso el valor mistérico y carácter iniciático de esta pieza, vinculable al pensamiento órfico en razón de la superposición entre la vida y la muerte.

De especial interés práctico resulta la Bô̂TE À OUTILS, con dos partes claramente diferenciadas. La primera (pp. 109-113) ofrece un preciso y sintético análisis de la estructura del trímetro yámbico, ya que el estudio métrico en el presente trabajo queda limitado a las partes no corales de la obra -en la bibliografía de este apartado (p. 113) se echa de menos el libro de M.L. West, Introduction to the Greek Metre. Oxford: Clarendon Press, 1987-, mientras que la segunda (pp. 113-117) contiene un léxico mitológico y geográfico de términos esenciales en esta pieza.

La BIBLIOGRAPHIE (pp. 119-124) presenta diversos apartados que van de las ediciones completas de Eurípides a las particulares de Alcestis, de obras de métrica griega, concordancias y escolios de Eurípides a obras generales sobre la historia, el pensamiento, la mitología la civilización griega o el teatro griego, pasando por estudios críticos sobre Eurípides y Alcestis en particular, junto a atros más específicos sobre el drama satírico.

Finalmente, el GLOSSAIRE (pp. 125-127) está integrado por una treintena de entradas que dan cuenta de diversos autores, definen términos métricos, 
nociones y categorías literarias, o explican diversas magistraturas, señalados a lo largo del texto con *, como se advierte en la p. 19.

\section{Lucien, Charon, Vies des philosophes à l'encan, Le Pêcheur, La Double accusation}

La INTRODUCTION (pp. 131-137) ofrece una síntesis crítica sobre la vida y obra de Luciano que permite situar y comprender la compleja personalidad creativa del escritor de Samosata $-c f$. la sección titulada UNE EUVRE INCLASSABLE-, siendo muy apreciable el cuadro cronológico de las pp. 136-137, en el que se recogen algunos de los escasos datos biográficos conocidos del autor y se relacionan los textos del programa con hechos históricos y con los principales sofistas y filósofos coetáneos de Luciano.

La sección REPÈRES se abre con sendas ilustraciones: la primera sitúa en un mapa de Atenas la ubicación de las distintas escuelas filosóficas (p. 141), mientras que la segunda (pp. 142-143) reproduce el mapa del Imperio romano a la muerte del emperador Cómodo (192 d. C.). Esta sección trata, en primer lugar, del contexto cultural en el que se contraponen filosofía -los diálogos del programa son de contenido filosófico- y Segunda Sofística, ya que esta constituye el principal movimiento literario y cultural de la época de Luciano, destacándose de forma especial la impronta -no solo formalde la retórica en la formación escolar de la época, cuando la palabra ocupa un lugar central, de lo que constituyeel hecho de que los sofistas sean las principales figuras intelectuales del período, tanto en su tarea de profesores de retórica como en su dimensión de artífices de espectáculos oratorios ante un público amplio y diverso: "Au-delà d'une liste de recettes pour composer un discours, la rhétorique propose aux hommes de l'Antiquité une manière de penser le monde qui les entoure et de le formuler... L'éducation et la culture grecques jouent donc le rôle d'un 'certificat de naturalisation' qui permet à un barbare d'acquérir et de revendiquer l'identité grecque, problématique essentielle à l'époque de la Seconde Sophistique" (p. 147). Es importante que se hayan dedicado también unas páginas al aticismo explicado aquí en su sentido restringido como fenómeno esencialmente lingüístico, y en su vertiente más amplia como proceso de imitación -el concepto de $\mu$ í $\mu$ $\sigma \mathrm{s}$ es crucial para entender la literatura griega de época imperial romana- de los modelos clásicos.

Las obras del programa están próximas entre sí por la cronología probable de su composición, así como por su afinidad temática: se trata de diálogos dramáticos puros que tratan cuestiones de índole filosófica. En cada caso se ofrece un resumen del contenido y desarrollo de la obra, 
seguidos de un esquema cuyos epígrafes dan cuenta no solo de la acción dramática y de sus protagonistas, sino también de los motivos tratados. Así, por ejemplo, a propósito de Le Pêcheur: 1-9 : L'ouverture du dialogue : la poursuite des philosophes contre Parrhésiades / 10-24 : La mise en place du procès présidé par philosophie / 25- 39 : Le procès : l'agôn / 40-52 : Le châtiment des faux philosophes (p. 155).

Habida cuenta de que los diálogos del programa se inscriben entre los de contenido filosófico -aunque siempre es arriesgado pretender clasificaciones definitivas en las obras de Luciano, como bien señala la autora (p. 134) - la BoÎTE À OUTILS reseña, como se indica de forma explícita (p. 201), los movimientos filosóficos, filósofos y escuelas que a lo largo de los cuatro diálogos son objeto de la sátira lucianesca: Pitágoras y el pitagorismo, Diógenes y el cinismo, Pirrón y el escepticismo, Crisipo y el estoicismo. En cada uno de estos bloques se sitúa cronológicamente el fundador de la escuela, se alude a sus discípulos más representativos y se hace referencia a los preceptos más importantes retomados por Luciano para caracterizar a sus filósofos. Porque al margen de los dogmas propios de cada escuela, de los preceptos y enseñanzas concretas que son cuestionados por Luciano, este sobre todo tiene como objetivo poner en evidencia las consecuencias nefastas de seguir a ultranza los mandatos de escuela, ya que tal actitud suele generar situaciones grotescas y ridículas, máxime cuando es habitual entre los filósofos contradecir con su comportamiento las propias enseñanzas y preceptos de escuela. En estas sintéticas pero eficaces páginas (pp. 201-209), la autora remite a pasajes concretos de los textos del programa -y también a otros autores y otras obras de Luciano- para ilustrar las correspondientes explicaciones en las que no faltan los términos griegos que mejor ejemplifican la esencia del pensamiento de las distintas escuelas o los atributos, físicos y conductuales que Luciano imputa a sus representantes. Así, por ejemplo, a propósito del cinismo: "La liberté de parole $(\pi \alpha \rho \rho \eta \sigma i ́ \alpha)$ et la brutalité de langage caractérisent donc le cynique (Vit. Auct. 8) qui manie la paradoxe, la raillerie, mais aussi l'insulte." (p. 204); o del epicureísmo: "De fait, Lucien distingue entre l'hédonisme des

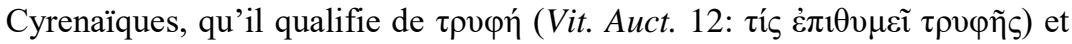
celui des épicuriens qui apparaît plus sobre (miel et figues, Vit. Auct. 19 et Bis acc. 20)" (p. 207).

La metodología seguida en el estudio sobre Luciano tiene un carácter más transversal por cuanto aquí Favreau-Linder no ha optado -y con gran acierto a nuestro entender- por tratar cada obra como una entidad aislada, sino como un punto de partida para abordar algunos temas fundamentales 
sobre Luciano, su tiempo y su obra con el telón de fondo de la filosofía, ya que, tomados como un conjunto por su contenido, también el análisis de su forma es útil para explicar cómo Luciano concibe su diálogo -un género nuevo, sin duda-, cómo lo articula y cómo se posiciona respecto a la filosofía y a sus representantes.

El apartado PROBLÉMATIQUes (pp. 157-197) se centra en la figura del autor, el diálogo lucianesco (elementos formales, innovación, tradición...), la relación del diálogo dramático con el teatro y de Luciano con los filósofos y la filosofía. En este estudio se aborda la cuestión de la difusión y presentación de las obras de Luciano, que tal vez no ha sido una de las más debatidas ni discutidas en los estudios sobre el autor de Samosata -cf. el artículo de reciente publicación F. Mestre, "Aspectos de la dramaturgia del diálogo en Luciano." Lexis 32 (2014): 331-355-, a pesar de que en sus obras hay referencias explícitas al público y a las circunstancias de la declamación (pp. 182-183), como en la prolaliá Zeuxis, donde demuestra una preocupación por reflexionar también sobre su propia creación y actividad literarias, siendo una muestra inequívoca de la madurez $-\mathrm{y}$ modernidad- de Luciano a propósito de su oficio, ya desde los inicios mismos de su carrera, no solo por el dominio de las técnicas de composición del texto, sino por revelar una conciencia clara de lo que pretende hacer. Asimismo, se incide en el carácter dramático del diálogo lucianeo y, por lo tanto, en la cuestión de si fueron solo leídos o también representados, dado que en los diálogos de Luciano -y en los del programa en particularpueden rastrearse distintos procedimientos propios de la escenografía teatral como son el movimiento escénico de los personajes ("Ainsi la totalité des Vies des philosophes à l'encan se présente comme une succession de saynètes délimitées par l'introduction puis la disparition d'un nouveau philosophe suivi de son acheteur", p. 185), los cambios de lugar y decorado, indicados la más de las veces por los propios personajes ("Le voyage des personnages lui-même peut être pensé en termes dramaturgiques : ascension sur une cime (Charon) ou à l'inverse vol de descente (Double accusation) seraient réalisables au moyen de la machinerie théâtrale, dont la grue $(\mu \eta \chi \alpha v \eta$ ) permet de tels mouvements vers ou depuis le sommet du bâtiment

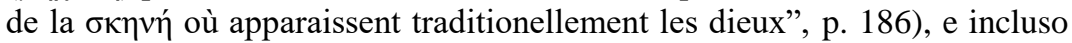
la distancia irónica manifestada en algunos personajes a propósito de la propia ficción inventada por el autor ("Parrhésiades moque sa propre folie de vouloir interroger un poisson, puisque chacun sait que les poissons sont muets (Pisc. 51)”, p. 187), conducentes todos estos recursos a presentar la propia vida humana bajo la metáfora del espectáculo teatral ("Charon et 
Hermès sont les spectateurs - le sous-titre du dialogue est les Observateurs - de la comédie tragique dont les hommes sont les acteurs inconscients", p. 187). En este trabajo se aborda también la debatida cuestión de la supuesta conversión a la filosofía tras abandonar la retórica -asunto que constituye el tema del diálogo Double accusation- y se enfatiza, al respecto, que Luciano no es un filósofo que pretenda dar lecciones morales, sino que aboga y respeta cualquier conducta moralmente ejemplar, porque entiende la filosofía como un modo de vida: Le Pêcheur se propone distinguir los verdaderos filósofos de los no filósofos, y Vies des philosophes à l'encan pone en escena diversos modos de filosofía, es decir diversos modos de vida. De ahí la utilidad de definir y explicar en su contexto, también literario, el término ßíos como equivalencia entre filosofía y vida "tel que Lucien l'emploie dans son dialogue Vies des philosophes à l'encan ( $\beta i ́ \omega v$ $\pi \rho \tilde{\alpha} \sigma 1 \varsigma) "$ (p. 195). Luciano, a través de sus dobles en las obras del programa, ilustra cuál es su posición respecto a la filosofía y cómo caracteriza a los filósofos cuyas vidas puestas en venta sirven, al mismo tiempo, como metáfora de la propia cultura en el seno de la sociedad romana ( $c f$. p. 197 con referencia a otras obras de Luciano).

La BIBLIOGRAPHIE está clasificada en ediciones, traducciones francesas y comentarios de las obras del programa, ediciones y traducciones de otras obras de Luciano, mientras que la bibliografía secundaria, además de incluir obras generales sobre Luciano -tal vez podría haberse añadido la monografía de J.L. Brandâo, A poética do Hipocentauro. Literatura, sociedade e discurso ficcional en Luciano de Samosata. Belo Horizonte: Editora UFMG. 2001; o el libro editado por A. Bartley, A Lucian for our times. Cambridge: C.U.P., 2009, particularmente el capítulo de K. Sidwell, "The Dead Philosophers' Society: New Thoughts on Lucian's Piscator and Eupolis' Demes", pp. 109-118 -, sobre el contexto sofístico-retórico y socio-histórico y sobre la biografía, se distribuye en cuatro apartados, dedicados, respectivamente, a una de las obras del programa (Charon), al yo del autor, a la relación de Luciano con la filosofía y al diálogo lucianesco como género y su vinculación con el teatro y la comedia $-c f$. M. Jufresa, "El teatre, metàfora de la vida a Llucià." Ítaca. Quaderns Catalans de Cultura Clàssica 19 (2003): 171-186-; estos últimos apartados se corresponden con los temas específicos abordados en el estudio.

Desde un punto de vista formal, cabe destacar el formato de libro, muy manejable para una publicación netamente instrumental como es esta, así como la presencia de muy pocos errores tipográficos, por ejemplo, 
Anthologixe por Anthologie (p. 125); DL VI, 22ucien... por DL VI, 22 et Lucien (p. 204).

Por encima de una finalidad concreta, los concursos, este libro es una herramienta útil también para estudiantes universitarios y, en general, para lectores interesados en conocer obras de la literatura griega: para unos como punto de partida, sistemático y bien organizado, para poder profundizar en los autores y obras seleccionados; para otros porque se ofrecen claves de lectura necesarias para una mejor aproximación e intelección de textos que, aun siendo atractivos por ellos mismos, adquieren mayor luz y perspectiva si su lectura va guiada por la mano de dos excelentes especialistas -J. Assaël en Eurípides y Favreau-Linder en Luciano-, porque solo un amplio conocimiento y dominio de estos textos y de sus autores, así como una familiaridad y competencia para abordar los puntos principales de su problemática, permite decir tanto y tan oportunamente en tan poco espacio. 